\title{
Production of Sugarcane Forecasting using ARIMAX Model
}

\author{
M Gopinath, M Kavithamani
}

\begin{abstract}
The main objective of this study is to analyze the production of sugarcane in India and to forecast the sugarcane production using Auto Regressive Integrated Moving Average with Exogenous variable or Inputs model (ARIMAX). This model mainly focused in the area of forecasting and it gives the accurate prediction. Data has been collected from Sugarcane Breeding Institute, Coimbatore. The ARIMAX model was introduced by Box and Tiao in their study. At present this model was used minimum amount of people in their studies. When we compare with ARIMA model, the ARIMAX model gives the greater accuracy.
\end{abstract} India.

Index Terms-Sugarcane, Prediction, ARIMA, ARIMAX,

\section{INTRODUCTION}

Sugarcane also called as 'Saccharum officinarum' which is grown all over in India. It also gives more employment opportunity to the millions of people who all are related to this field. Sugarcane was developed in 'New Guinea' 1000 years before forming of sugarcane have been started in vedic period. In earliest day the cultivation of sugarcane is found in 1400-1000 B.C in Indian writings. Now a day's world accepted that India is the home for saccharum species.

There are different climatic place for sugarcane cultivation in all over India. i.e tropical region and subtropical region. There are five climatic area is identified for the purpose of development of sugarcane. (i). Northwest area (ii). North central area (iii). Northeast area (iv). Penisular area (v). Coastal area. The type of a zone called tropical given $45 \%$ and $55 \%$ of total amount of production in India. In subtropical zone the production of sugarcane is vise-versa (55\% and $45 \%)$.

The growth of sugarcane is high when the climatic condition should be in between latitude 36.70 northern area and 31.00 for southern areas of the equator enlarging tropical to subtropical. The weather condition alone decides the productivity of sugarcane and juice conditions. In sugarcane production Maharashtra plays vital role in India, it covers the area of 9.4 lakh, with produces 61.32 million ton and Tamilnadu is also produce sugarcane high. The lower production of sugarcane is only in the state Bihar. One of the largest agro-based production industries is sugarcane.

Gur and kandsari in sugarcane:

Gur is the legitimate commodity of sugarcane and it is also called as unrefined sugar form. Gur is like brown

Revised Manuscript Received on September 14, 2019.

M Gopinath, Department of Mathematics and Statistics, Sri Krishna Arts and Science College, Coimbatore, Tamil Nadu, India.(E-mail: gopimalaisamy@gmail.com)

M Kavithamani, Department of Mathematics and Statistics, Sri Krishna Arts and Science College, Coimbatore, Tamil Nadu, India.(E-mail: statisticskavi@yahoo.co.in) coloured around full of sucrose, so that the colour of gur being brown. Making of gur is much easier than making of sugar, because no need of frequent refinement process to make gur. The gur is mainly used to make sweet items and it is usually the consuming commodity. In India the production of gur is abot $60 \%$, and the country Brazil is a top most exporter of jaggery.

Kandsari is a classical organic unprocessed sugar that consist fragment minerals and fibre. Kandsari is made with a help of cold raw juice of sugarcane. Without adding any chemicals the organic form of biggest sugar called kandsary and it is a kind of unrefined sugar in a large size.

\section{Objective:}

The main objective of our study is to establish a relevant ARIMAX model to be measure the production of sugarcane forecasting using ARIMAX model. The major objective of this study is based on Autoregressive Integrated Moving Average with exogenous variable (ARIMAX) to several kind of sugarcane production such as seed and feed(\%) and Gur \& khansari as exogenous variable

\section{REVIEW OF LITERATURE}

There are several author have been worked under this ARIMAX model but in the area of agriculture there are very few of them have been worked under the ARIMAX model. Mohammed Amir Hamjah (2014) have applied this model with a title "Climatic Effects on major pulse in Bangladesh an application of Box-jenkins ARIMAX model "In this study they conclude that instead of using other models such as ARIMA,SARIMA etc.. suggested that ARIMAX for best prediction. Uyothu Amekauma Victor-Edema, ProofIsaac Didi Essi (2016) in the title" The ARIMAX for Nigerian non-oil Export" in this study the author have been explained about ARIMAX model fitting, reason for choosing $\mathrm{X}$ as a exogenous variable and also given a figure to show the roots of characteristics polynomial. Mofeng YANG, Jiaohong XIE, Peipei MAO, Chao WANG, Zhirui YE (2018) on the topic "Application of ARIMAX on Forecasting Freeway Traffic Flow" have been discussed about ARIMAX model implementation, Stationary test, Series differencing, ARIMA parameter estimation, in that they discovered both ARIMA and ARIMAX model which gives better performance in urban areas compare to sub-urban areas. Durka peter and Pastorekova Silvia worked under the topic" ARIMA vs ARIMAX - based on these two analysis which approach is enhanced to analyse and forecast the macroeconomic time series models?" have been 
distinguished between ARIMA and ARIMAX and finally they proved that ARIMA model is nearly seems to be an scientific model rather than ARIMAX model.

\section{METHODOLOGY}

A time series means that a number that represents the measures of certain activity more equally gaps time interval. It is on among the method which is mainly focused historical record in an equal interval space with consistency in measurement.

\section{Method of Moving Average:}

Method of Moving average models was proposed by Slutsky (1927) and Wold (1938). The series of moving average can be written as

$$
Y_{t}=\varepsilon_{t}-\theta_{1} \varepsilon_{t-1}-\theta_{2} \varepsilon_{t-2}-\theta_{3} \varepsilon_{t-3}-\ldots-\theta_{q} \varepsilon_{t-q}
$$

This is called as method of moving average in the order $q$ (MA q) here $Y_{t}$ is the series which contains original data and $\varepsilon_{t}$ is the error term of the series.

\section{Method of Auto Regressive Process:}

The Auto Regressive process was first proposed by Yule (1926) this regressive process is specially satisfies the following equation

$$
Y_{t}=\phi_{1} Y_{t-1}+\phi_{2} Y_{t-2}+\phi_{3} Y_{t-3}+\ldots+\phi_{p} Y_{t-p}
$$

The present value $Y_{t}$ is called as linear combination for $\mathrm{p}$ (AR P) also $\varepsilon_{t}$ is the assumption of independent of $Y_{t-1}, Y_{t-2}, Y_{t-3} \ldots Y_{t-q}$.

The Auto Regressive Integrated Moving Average (ARIMA):

The ARIMA methodology was proposed by the author Box and Jenkins in the year 1976. This ARIMA model is also called as Box- Jenkins model. This model is based on the error term of the time series. To get conclude time series the data should be stationary which means, the mean, variance and covariance are constants over the time period. For this we can write the ARIMA model equation as follows.

$$
\begin{aligned}
& Y_{t}=\phi_{1} Y_{t-1}+\phi_{2} Y_{t-2}+\phi_{3} Y_{t-3}+\ldots \phi_{p} Y_{t-p}+\phi_{1} Y_{t-s} \\
& +\phi_{2} Y_{t-2 s}+\ldots+\phi_{p} Y_{t-p s}+a_{t}-\theta_{1} a_{t-1}-\theta_{2} a_{t-2}- \\
& \ldots-\theta_{q} a_{t-q}-\Theta_{1} a_{t-s}-\Theta_{2} a_{t-2 s}-\ldots \Theta_{q} a_{t-q s}
\end{aligned}
$$

With a help of back shift operator (lag) we write the above equation as follows:

$$
\phi_{p}(B) \phi_{p}\left(B^{s}\right) z_{t}=\theta_{q}(B) \Theta_{q}\left(B^{s}\right) a_{t}
$$

Here:

$$
\begin{aligned}
& z_{t}=(1-B)^{d}\left(1-B^{s}\right)^{D} \ln \left(Y_{t}\right) \\
& \phi_{p}(B)-\text { Non seasonal operator of }
\end{aligned}
$$

Autoregressive process $A R(p)$
The Auto Regressive Integrated Moving Average with Exogenous variable (ARIMAX):

This model is a development of Autoregressive Integrated Moving Average (ARIMA). This ARIMA consist of three parameters specifically $\mathrm{p}, \mathrm{d}$ and $\mathrm{q}, \mathrm{p}$ represent term of auto regressive, $q$ represents the term of moving average and $d$ is used to make the term stationary. The ARIMA $(p, q)$ model is expressed as follows:

$$
\phi(L) \cdot \Delta^{d} Y_{t}=\theta(L) \varepsilon_{t}
$$

Where

$\phi(L)$ is the autoregressive polynomial and it is exp ressed as

$$
\phi(L)=\left(1-\phi_{1} L^{1}-\phi_{2} L^{2}-\ldots-\phi_{p} L^{p}\right.
$$

And

\section{$\theta(L)$ is called the moving average polinomial and}

it is exp ressed as

$$
\theta(L)=\left(1-\theta_{1} L^{1}-\theta_{2} L^{2}-\ldots \theta_{q} L^{q}\right.
$$

$Y_{i}$ is the dependent variable in time t, $\Delta^{d}$ is represent as degree of difference and $\varepsilon_{t}$ is the process of white noise. By adding equation (6) we get

$$
\begin{aligned}
& \phi(L) \cdot \Delta^{d} Y_{t}=\varphi(L) X_{t}+\theta(L) \varepsilon_{t} \\
& \text { Where } \\
& \qquad \varphi(L)=\left(1-\varphi_{1} L^{1}-\varphi_{2} L^{2}-\ldots-\varphi_{r} L^{r}\right)
\end{aligned}
$$

The equation (8) represents the usual form of ARIMAX (p,d,q) model.

\section{Model Fitting:}

In ARIMAX model also called Box-Jenkins with exogenous variable model adopts certain approach like identification of the problem, forecasting and diagnostic checking also checked the given information, missing value of the data are stationary. In this work I applied Augmented Dickey-Fuller (ADF) test to obtain the conformation of the stationary series. Here applied Autocorrelation function (ACF) and partial autocorrelation function (PACF) have combined together to get the order of $\mathrm{AR}$ and $\mathrm{MA}$ of this model. With a help of Akaike information criterion (AIC) the suitable model has been selected for this study.

\section{RESULTS AND DISCUSSION}

The following figures are explains about the production of sugarcane for million tons, their seed and feed in percentage and gur \& khandsari in percentage. In the figure -1 , shows that there is a gradual increase in the pattern of production of sugarcane over a period of time. The figure-3 shows that there is gradual increase in seed and feed for a while and suddenly it comes very low for a particular year and started increasing trend. The figure- 5 shows that gradual decrease from the starting year itself. The first difference of the variable production of sugarcane, seed and feed and gur $\&$ khandasari with $(\mathrm{p}$-value $=0.0000)$. 
The ARIMAX model gives the effects of production on seed and feed and gur and khandsari. The autocorrelation function (ACF) explains that autoregressive model capable of order 1. i.e. $\mathrm{AR}(1)$ when the partial autocorrelation function (PACF) Explains that a moving average capable order 2. i.e. MA(2). Comparatively the models make use of Akaike information criteria (AIC), the appropriate model has been developed as ARIMAX $(1,1,2)$.

Production of Sugarcane (million tons)

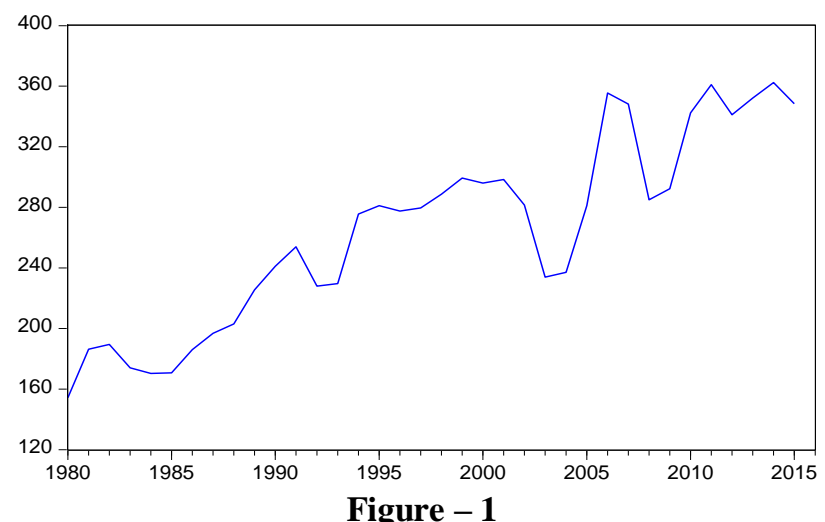

Differenced Production of Sugarcane (million tons)

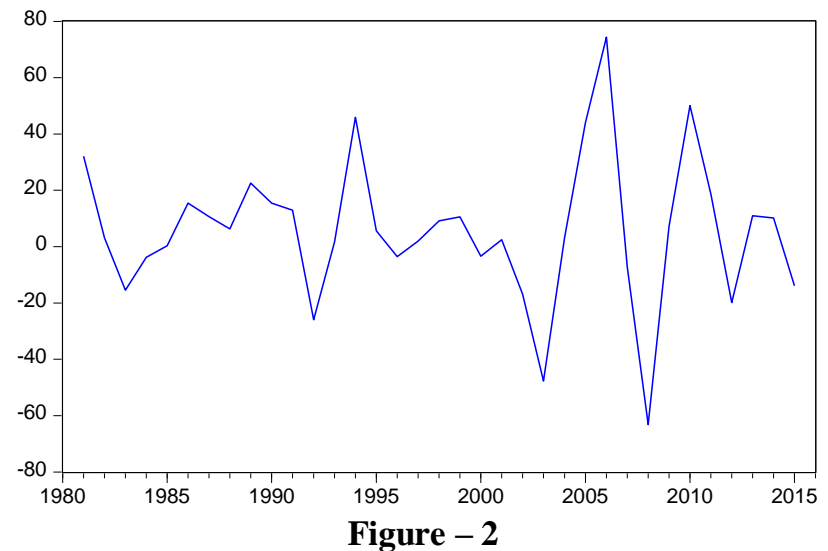

Seed \& Feed $(\%)$

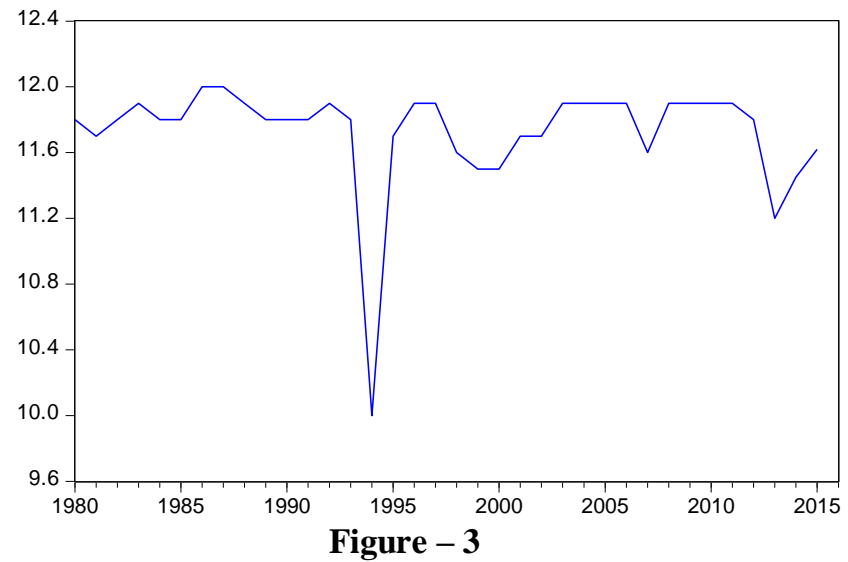

Differenced Seed \& Feed (\%)

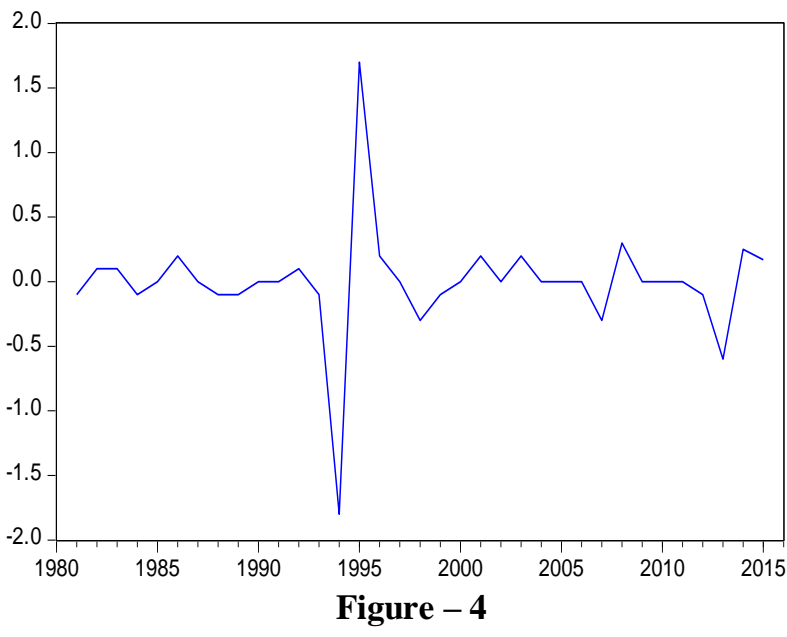

Gur \& Khandsari (\%)

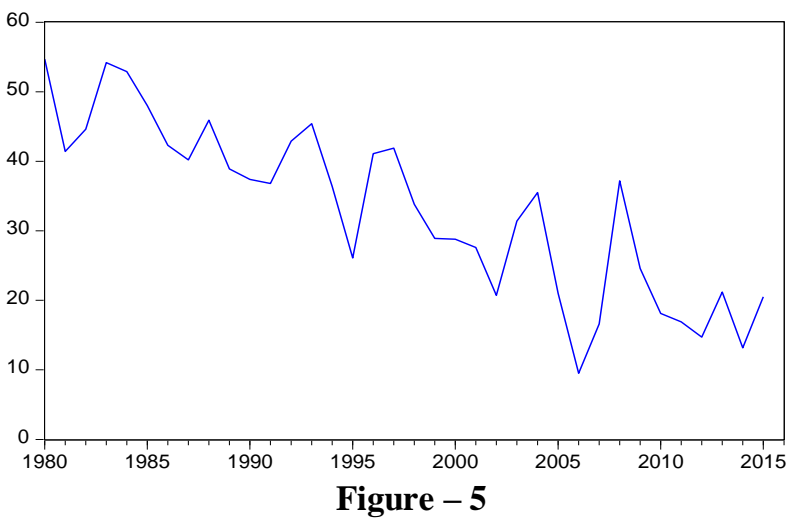

Differenced Gur \& Khandsari (\%)

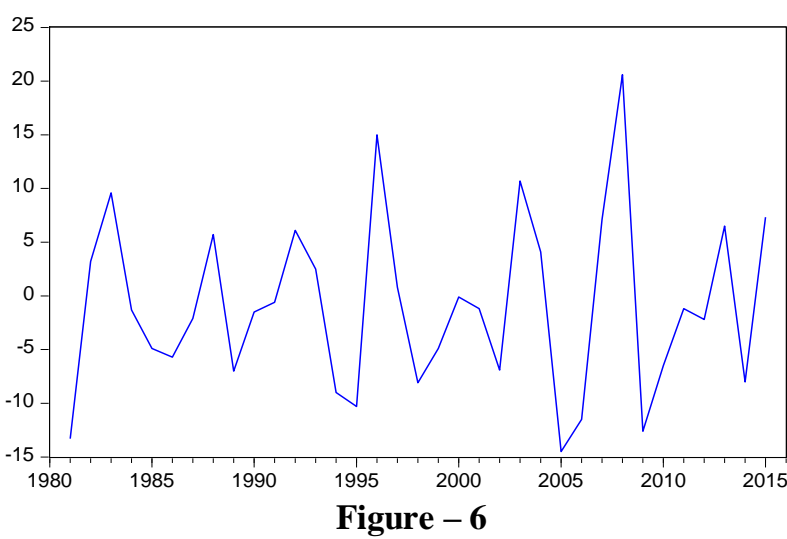

The ADF test for the variable production of sugarcane ( $\mathrm{p}$ value $=0.7691)$, seed and feed $(p$-value $=0.0002)$ and gur $\&$ khansari $(\mathrm{p}$-value $=0.8096)$ these values have obtained at 0.05 level of significance, as non-stationary. 
Production of Sugarcane Forecasting using ARIMAX Model

\begin{tabular}{|c|c|c|c|c|c|c|c|c|}
\hline \multicolumn{5}{|c|}{ Autocorrelation Partial Correlation } & \multirow{2}{*}{$\begin{array}{l}\text { AC } \\
0.879\end{array}$} & \multirow{2}{*}{$\begin{array}{l}\text { PAC } \\
0.879\end{array}$} & \multirow{2}{*}{$\begin{array}{l}\text { Q-Stat } \\
34.048\end{array}$} & \multirow{2}{*}{ Prob } \\
\hline 1 & & I & & 1 & & & & \\
\hline 1 & $\square$ & 미 & 1 & 2 & 0.729 & -0.192 & 58.064 & 0.000 \\
\hline I & 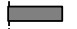 & 1 & $\square$ & 3 & 0.673 & 0.357 & 79.096 & 0.000 \\
\hline I & $\square$ & I & I & 4 & 0.650 & -0.017 & 99.201 & 0.000 \\
\hline 1 & $\square$ & 1 미 & 1 & 5 & 0.570 & -0.161 & 115.10 & 0.000 \\
\hline I & $\square$ & I & 1 & 6 & 0.473 & 0.007 & 126.38 & 0.000 \\
\hline 1 & $\square$ & I & 1 & 7 & 0.423 & 0.043 & 135.64 & 0.000 \\
\hline 1 & $\square$ & 14 & 1 & 8 & 0.380 & -0.101 & 143.37 & 0.000 \\
\hline I & $\square$ & 1 & I & 9 & 0.294 & -0.122 & 148.13 & 0.000 \\
\hline I & 口 & I & 1 & 10 & 0.207 & 0.011 & 150.57 & 0.000 \\
\hline 1 & 口 & I & I & 11 & 0.159 & -0.022 & 152.05 & 0.000 \\
\hline 1 & 口 & I & 1 & 12 & 0.134 & 0.031 & 153.14 & 0.000 \\
\hline 1 & D & & 1 & 13 & 0.098 & 0.018 & 153.75 & 0.000 \\
\hline 1 & 1 & 14 & I & 14 & 0.042 & -0.085 & 153.86 & 0.000 \\
\hline I & 1 & 1 & I & 15 & 0.006 & 0.045 & 153.87 & 0.000 \\
\hline 1 & I & 14 & 1 & 16 & -0.022 & -0.090 & 153.90 & 0.000 \\
\hline 1 & 1 & 1 & 1 & 17 & -0.063 & -0.039 & 154.19 & 0.000 \\
\hline 1 प & 」 1 & 14 & 1 & 18 & -0.125 & -0.120 & 155.38 & 0.000 \\
\hline I다 & 」 1 & 10 & I & 19 & -0.176 & -0.040 & 157.87 & 0.000 \\
\hline I다 & ప 1 & 14 & I & 20 & -0.208 & -0.049 & 161.49 & 0.000 \\
\hline
\end{tabular}

Table - 1

\begin{tabular}{|c|c|c|c|c|c|c|c|c|}
\hline \multicolumn{5}{|c|}{ Autocorr... Partial Correl... } & \multirow{2}{*}{$\begin{array}{l}\mathrm{AC} \\
0.184\end{array}$} & \multirow{2}{*}{$\begin{array}{c}\text { PAC } \\
0.184\end{array}$} & \multirow{2}{*}{$\frac{\text { Q-Stat }}{1.4641}$} & \multirow{2}{*}{ Prob } \\
\hline $\mathbf{I}$ & י & $\mathbf{I}$ & & 1 & & & & \\
\hline & $\mathbf{I}$ & & 1 & 2 & -0.639 & -0.697 & 19.520 & 0.000 \\
\hline$\square$ & I & 14 & । & 3 & -0.364 & -0.071 & 25.527 & 0.000 \\
\hline $\mathbf{I}$ & 口 & 미 & 1 & 4 & 0.212 & -0.223 & 27.618 & 0.000 \\
\hline I & 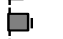 & 10 & । & 5 & 0.274 & -0.097 & 31.213 & 0.000 \\
\hline $\mathbf{I}$ & $\mathbf{I}$ & ' & & 6 & -0.055 & -0.182 & 31.362 & 0.000 \\
\hline $\mathbf{I}$ & $\mathbf{I}$ & $\mathbf{I}$ & & 7 & -0.048 & 0.207 & 31.479 & 0.000 \\
\hline $\mathbf{I}$ & $\mathbf{I}$ & 미 & 1 & 8 & -0.015 & -0.252 & 31.492 & 0.000 \\
\hline I & 1 & I & 1 & 9 & -0.087 & 0.051 & 31.900 & 0.000 \\
\hline I & 1 & لם1 & 1 & 10 & -0.049 & -0.167 & 32.033 & 0.000 \\
\hline I & 1 & 1 & I & 11 & 0.034 & -0.083 & 32.102 & 0.001 \\
\hline I & י & 1 & I & 12 & 0.126 & -0.031 & 33.049 & 0.001 \\
\hline $\mathbf{I}$ & I & 1며 & 1 & 13 & -0.026 & -0.176 & 33.091 & 0.002 \\
\hline 1미 & 1 & 1ם & 1 & 14 & -0.162 & -0.162 & 34.777 & 0.002 \\
\hline $\mathbf{I}$ & 1 & 14 & 1 & 15 & -0.011 & -0.059 & 34.785 & 0.003 \\
\hline I & I & 14 & 1 & 16 & 0.121 & -0.144 & 35.805 & 0.003 \\
\hline I & 1 & 14 & 1 & 17 & 0.061 & -0.128 & 36.074 & 0.004 \\
\hline $\mathbf{I}$ & 1 & 14 & 1 & 18 & -0.067 & -0.058 & 36.418 & 0.006 \\
\hline 1 & 1 & 1 & 1 & 19 & 0.027 & 0.064 & 36.475 & 0.009 \\
\hline 1 & י & 1 & 1 & 20 & 0.098 & -0.014 & 37.284 & 0.011 \\
\hline
\end{tabular}

Table - 2

Table -1 represent the auto correlation function for the data. It shows that our data is not stationary. Then move on to the next step called first differenced auto correlation. Table -2 shows that the data is stationary.

ADF Test

t-Statistic Prob. *

\begin{tabular}{llll}
\hline \hline & & & \\
& & & \\
& & & \\
\hline \hline $\begin{array}{l}\text { Augmented Dickey-Fuller test } \\
\text { statistic }\end{array}$ & -0.452008 & 0.8896 \\
\hline Test critical values: & $1 \%$ level & -3.615588 & \\
& $5 \%$ level & -2.941145 & \\
& $10 \%$ level & -2.609066 & \\
\hline \hline
\end{tabular}

*MacKinnon (1996) one-sided p-values.

Table -3
ADF Test for difference

t-Statistic Prob.

\begin{tabular}{lccc}
\hline \hline $\begin{array}{l}\text { Augmented Dickey-Fuller test } \\
\text { statistic }\end{array}$ & -9.164991 & 0.0000 \\
\hline Test critical values: & $\begin{array}{c}1 \% \text { level } \\
5 \% \text { level } \\
10 \%\end{array}$ & -2.615588 & \\
& $\begin{array}{l}\text { level } \\
\text { level }\end{array}$ & -2.609066 \\
& \\
\hline \hline
\end{tabular}

${ }^{\star}$ MacKinnon (1996) one-sided p-values.

Table -4

To check further our data is stationary, the Phillips-Perron Unit root test is also conducted and the result has been given in the table - 3. It shows the data is non-stationary therefore we conduct the first differenced ADF test, hence it is found that the data became stationary and it has been shown in table -4 .

\section{Augmented Dickey-Fuller Test Equation \\ Dependent Variable: D(PRODUCTION OF SUGARCANE)}

\begin{tabular}{lrlll}
\hline \hline \multicolumn{1}{c}{ Variable } & Coefficient & Std. Error t-Statistic & Prob. \\
\hline \hline SUGARCANE_(-1) & -0.055341 & $0.060142-0.920166$ & 0.3651 \\
D(SUGARCANE_(-1)) & 0.364963 & 0.135243 & 2.698562 & 0.0115 \\
D(SUGARCANE_(-2)) & -0.661789 & $0.134349-4.925895$ & 0.0000 \\
\multicolumn{1}{c}{ C } & 21.66137 & 16.12981 & 1.342941 & 0.1897 \\
\hline \hline R-squared & 0.520284 & Mean dependent v & 4.816455 \\
Adjusted R-squared & 0.470658 & S.D. dependent var & 26.00468 \\
S.E. of regression & 18.91993 & ADF & 8.831522 \\
Sum squared resid & 10380.95 & SBC & 9.012916 \\
Log likelihood & -141.7201 & Hannan-Quinn & 8.892555 \\
F-statistic & 10.48415 & Durbin-Watson stat & 2.035684 \\
Prob (F-statistic) & 0.000077 & & \\
\hline \hline
\end{tabular}

Table - 5

Based on the diagnostic test we have selected the ARIMAX model as bellow Table - 6. It shows that the ARIMAX $(1,2,2)$ and the SMA (18) also found. With a help of diagnostic testing we have chosen thesis $\mathrm{p}$ and $\mathrm{q}$. The quality of the ARIMAX model have chosen with a help of the program and it is listed in the below table. 
Dependent Variable: D(PRODUCTION_OF_SUGARCANE_) Method: ARMA Maximum Likelihood (OPG-BHHH)

\begin{tabular}{|c|c|c|c|}
\hline Variable & Coefficient & Std. Error t-Statistic & Prob. \\
\hline $\mathrm{C}$ & 67.53746 & 92.319470 .731562 & 0.4705 \\
\hline SEED FEED & -5.232068 & $7.755292-0.674645$ & 0.5054 \\
\hline GUR KHANDSARI & -0.013975 & $0.285143-0.049011$ & 0.9613 \\
\hline $\mathrm{AR}(1)$ & 0.322231 & 0.1800581 .789594 & 0.0843 \\
\hline $\mathrm{MA}(2)$ & -1.000000 & $3033.849-0.000330$ & 0.9997 \\
\hline $\operatorname{SMA}(18)$ & -1.000000 & $21638.91-4.62 \mathrm{E}-05$ & 1.0000 \\
\hline SIGMASQ & 156.3222 & 1612560. 9.69E-05 & 0.9999 \\
\hline R-squared & 0.755405 & Mean dependent & 5.54857 \\
\hline Adjusted R-squared & 0.702992 & S.D. dependent var & 25.6496 \\
\hline S.E. of regression & 13.97865 & Akaike info criterion & 9.03038 \\
\hline Sum squared resid & 5471.276 & Schwarz criterion & 9.34145 \\
\hline Log likelihood & -151.0317 & Hannan-Quinn criter. & 9.13776 \\
\hline F-statistic & 14.41253 & Durbin-Watson stat & 1.85114 \\
\hline Prob (F-statistic) & 0.000000 & & \\
\hline
\end{tabular}

Table - 6

\section{Forecasting:}

This forecasting is based on the past time series data (1975 to 2016) the forecasted values are shown in the table 7.The forecasted diagram - 7 is also given.

Forecasting of Sugarcane from 2017-2025 PRODUCTION FORECASTING

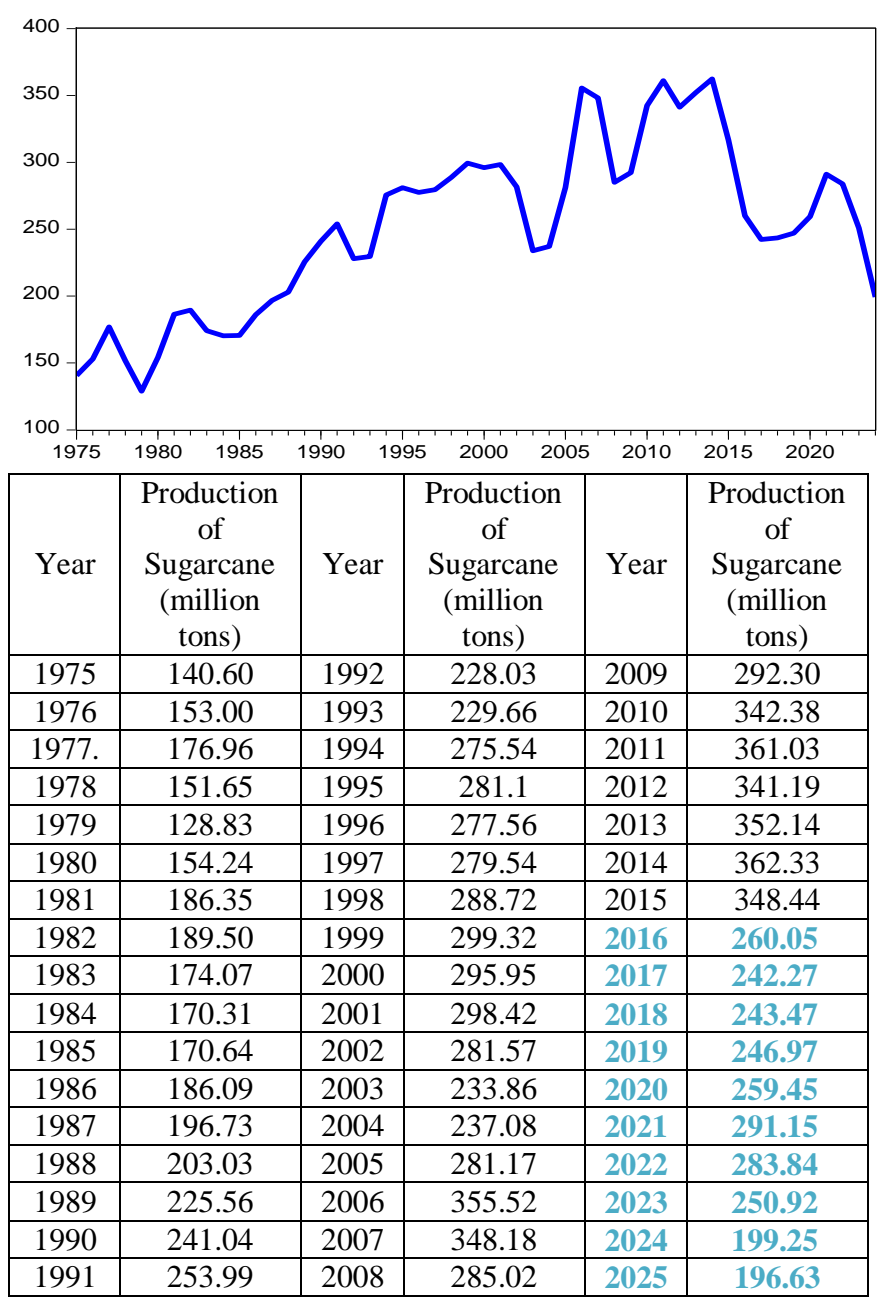

\section{CONCLUSION}

In this article, we have constructed a special model called ARIMAX. Based on this model we came to know the future values which means that the forecasting value of sugarcane production 2015 to 2026 . The figure -7 is clearly explains the future production of sugarcane per million also Table -7 explains that the amount of change in future production. This indicates that there will be a gradual decrease production of sugarcane; we should take the necessary steps in order to improve the production.

\section{REFERENCES}

1 Box, G. E. P. - Jenkins, G. M. - Reinsel, G. C.: Time Series Analysis: Forecasting and Control. John Wiley \& Sons Inc., New York, 2008.

2 Box, G. E. P. - Tiao, G. C.: Intervention analysis with applications to economic and environmental problems. Journal of the American Statistical Association. 1975, vol. 70, no. 349, p. 70-79.

3 Marek, L.: Transfer function models. Acta Oeconomica Pragnesia. 2000, vol. 8, no. 3, p. 83-94

4 Pankratz, A.: Forecasting with Dynamic Regression Models. Wiley-Interscience, 1991.

5 Rublíková, E. - Marek, L.: Linear transfer function model for outflow rates. Ekonomické rozhl'ady. 2001,vol,30,no. 4, p.457 - 466.

6 De Felice, M., Alessandri A., Ruti P. M.,(2013). Electricity demand forecasting over Italy: potential benefits using numerical weather prediction models. Electric Power Systems Research. Retrieved on 16/10/2015 www.researchgate.net/publication/263927 372

7 Wangi K., Singhasivanon, P., Silawan, T., Lawpoolsri, S., White, N. J.,\& Kaewkungwal, J. (2010). Development of temporal modeling for forecasting and prediction of malaria infections using time series and ARIMAX analysis: a case study in endemic districts of Bhutan. Malaria Journal. 9(251).

8 8.L.R.Dhumne,"Electroniccommerce:acurrenttrend,"Inte rnationalJournalonInformationTechnologyManagement, 2 012.

9 X. Q. Zhang and S. W. Chen, "Forecast of Chinas Forestation Area Based on ARIMA Model," Chinese Forestry Science \& Technology, vol.5, no.2,pp. 5055,2010 .

10 K. W. Wang, C. Deng, and J. P. Li, "Hybrid methodology for tuberculosis incidence time-series forecasting based on ARIMA and a NAR neural network," Epidemiology \& Infection, vol. 1, 2017.

11 S.Wei, D.Zuo, and J.Song, "Improving prediction accuracy of river discharge time series using a WaveletNAR artificial neural network," Journal of Hydro informatics, vol. 14, no. 4, pp. 974-991,2012.

12 P. Geng, L. Na, and L. Ben-Fu, "Research on the Prediction of E-commerce Transaction Volume-Based on the Prediction Model of Search Data and Commodity Classification in Station,"Management Modernization, vol.2,pp.30-32,2014 